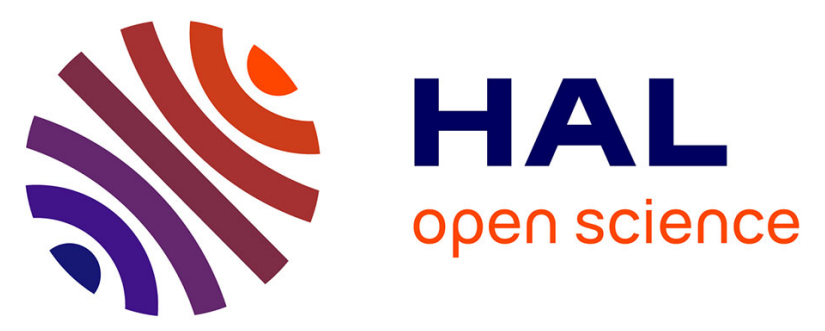

\title{
A Comparative Study of Two Fault-Tolerant Dual-Motor Drive Topologies Under Short-Circuit Inverter Switch Fault
}

Tiago Jose dos Santos Moraes, Ngac-Ky Nguyen, Fabien Meinguet, Eric Semail

\section{To cite this version:}

Tiago Jose dos Santos Moraes, Ngac-Ky Nguyen, Fabien Meinguet, Eric Semail. A Comparative Study of Two Fault-Tolerant Dual-Motor Drive Topologies Under Short-Circuit Inverter Switch Fault. International Symposium on Industrial Electronics, Jun 2015, Buzios, Brazil. pp.1490 - 1495, 10.1109/ISIE.2015.7281694 . hal-01357945

\section{HAL Id: hal-01357945 \\ https://hal.science/hal-01357945}

Submitted on 30 Aug 2016

HAL is a multi-disciplinary open access archive for the deposit and dissemination of scientific research documents, whether they are published or not. The documents may come from teaching and research institutions in France or abroad, or from public or private research centers.
L'archive ouverte pluridisciplinaire HAL, est destinée au dépôt et à la diffusion de documents scientifiques de niveau recherche, publiés ou non, émanant des établissements d'enseignement et de recherche français ou étrangers, des laboratoires publics ou privés. 


\title{
A Comparative Study of Two Fault-Tolerant Dual- Motor Drive Topologies Under Short-Circuit Inverter Switch Fault
}

\author{
Tiago José dos Santos Moraes ${ }^{1}$, Ngac Ky Nguyen ${ }^{1}$, Fabien Meinguet ${ }^{2}$, Eric Semail ${ }^{1}$ \\ ${ }^{1}$ Electrical Engineering and Power Laboratory of Lille (L2EP) \\ Arts et Métiers ParisTech, Lille, France \\ ${ }^{2}$ Thales Alenia Space, Charleroi, Belgium \\ E-mail. ${ }^{1}\{$ tiago.dossantosmoraes ;ngacky.nguyen ; eric.semail $\} @$ ensam.eu \\ ${ }^{2}$ fabien.meinguet@thalesaleniaspace.com
}

\begin{abstract}
This paper analyzes two dual-motor fault-tolerant topologies for aerospace thruster application. The first structure supplies independently both machines while the second one connects them in series for reducing the number of transistors and offering a capability of energy management between the sources. Inverter short-circuit fault is considered. Based on the peak-currents obtained in simulation in degraded mode without reconfiguration and with two different reconfiguration strategies, the two proposed topologies can be compared in economic and technical aspects.
\end{abstract}

Keywords-series connected; multiphase machines; openwinding; fault-tolerance; reconfiguration; short-circuit fault; TVC system; dual-drives; dual-motor.

\section{NOMENCLATURE}

$\varphi$

Angle of the direction of the thrust inclination

$\boldsymbol{\theta}$ Inclination angle of the thrust

$\Omega_{j} \quad$ Speed of the ' $j$ ' machine

$\boldsymbol{i}_{\boldsymbol{j} i} \quad$ Current of the phase ' $\mathrm{i}$ ' of the machine ' $\mathrm{j}$ '

$\boldsymbol{i}_{\boldsymbol{h i j}} \quad$ Current of the fictitious homopolar machine ' $\mathrm{i}$ ' of the machine ' $\mathrm{j}$ '

$\boldsymbol{i}_{\boldsymbol{m} \boldsymbol{\alpha} \boldsymbol{j}}, \boldsymbol{i}_{\boldsymbol{m} \boldsymbol{\beta} \boldsymbol{j}} \quad$ Current $\alpha$ and $\beta$ of the fictitious main machine of the machine ' $\mathrm{j}$ '

$\boldsymbol{i}_{\boldsymbol{s} \alpha \boldsymbol{j}}, \boldsymbol{i}_{\boldsymbol{s} \boldsymbol{\beta} \boldsymbol{j}} \quad$ Current $\alpha$ and $\beta$ of the fictitious secondary machine of the machine ' $\mathrm{j}$ '

$\left[\boldsymbol{I}_{\boldsymbol{m} j}\right],\left[\boldsymbol{I}_{\boldsymbol{s} j}\right]$ Currents of the fictitious main and secondary machines of the machine ' $\mathrm{j}$ '

$[\boldsymbol{K}] \quad$ Coupling matrix

$\left[\boldsymbol{C}_{6}\right] \quad$ Concordia matrix for a 6-phases symmetric machine

$\boldsymbol{P}_{\boldsymbol{m e c j}} \quad$ Mechanic power generated by machine ' $\mathrm{j}$ '

$\boldsymbol{R}_{\boldsymbol{m}}, \boldsymbol{R}_{\boldsymbol{s}} \quad$ Resistance of the main and secondary machines

$\boldsymbol{\omega}_{\boldsymbol{j}} \quad$ Electric frequency of machine ' $\mathrm{j}$ '

$\boldsymbol{L}_{\boldsymbol{m}}, \boldsymbol{L}_{\boldsymbol{s}} \quad$ Inductance of the main and secondary machines
$\boldsymbol{V}_{\boldsymbol{m} \boldsymbol{\alpha} \boldsymbol{\beta}}, \boldsymbol{V}_{\boldsymbol{s} \boldsymbol{\alpha} \boldsymbol{\beta}}$ Tension of the main and secondary machines in $\alpha \beta$ reference

$v_{N 1 N 2} \quad$ Voltage between the neutral points of both DC sources

$\boldsymbol{V}_{\boldsymbol{D C}} \quad$ DC bus voltage

$\boldsymbol{I}_{\boldsymbol{p} \boldsymbol{k}} \quad$ Peak current in degraded mode

$\boldsymbol{S}_{\text {sw }} \quad$ Apparent power of the transistor

$\boldsymbol{S}_{\boldsymbol{g l}} \quad$ Global apparent power of the converter

$N_{\text {sw }} \quad$ Number of transistors

\section{I.INTRODUCTION}

The application of the system analyzed in this paper is an aerospace Thrust Vector Control (TVC) system which needs to use simultaneously two electrical drives in order to properly control the direction of the thruster (see Fig. 1). For most of aerospace applications, fault-tolerance capability is highly required [1][2][3]. Fault-tolerance is achieved by supplementary Degrees of Freedoms (DoF) which ensure an acceptable operating system. For an inverter-machine drive, supplementary DoF can be presented in the form of supplementary inverter legs and/or multiphase machines [2][6].

In the present paper, fault-tolerance of two topologies is analyzed under inverter short-circuit fault. As highlighted in [4], short-circuit faults are the most constraining ones because of high peak-currents generated. A specific fault tolerant control has the purpose of reducing torque oscillation and, consequently, the peak-currents in degraded mode [6][7]. Because of this, two degraded modes with different hardware reconfigurations were included in this paper analysis.

Both topologies are open-winding and composed of two symmetrical six-phase machines. The first topology is a classical H-bridge drive (Fig. 3), while the second one presents a series connection between the machines (Fig. 4) where the number of transistors is halved. A decrease of the number of current sensors, transistors and, consequently, the number of drivers compared to a classical topology, allows a global cost 
and mass reduction. That is particularly true if the switch ratings do not increase drastically for the series connected machine topology. Besides, as the series-connection topology presents a higher value of inductive components in comparison with the H-bridges topology, currents harmonics amplitude, which may reach high values in degraded mode, are expected to be lower. On contrary, as currents cross both machines even if only one is driven, the copper losses raises and subsequently the global efficiency are expected to be lower.

Series connected machines in the $2^{\text {nd }}$ topology will only be considered as a better solution if the global cost (investment cost and running cost) are lower than the concurrent topologies. Short time missions (e.g. thruster) may appear as an application in accord with the series connection topology, because the running cost tends to be negligible in comparison with the investment cost.

In series connection topology, an independent control of each machine requires a specific coupling. Some papers [8][11], demonstrate that the number of DoF (in this case, independent currents) has to be higher than twice the number of machines, in a case of a sinusoidal back electromotive force (Back-EMFs). Otherwise, a more complex control using supplementary DoF is required for the torque oscillation compensation [11].

The paper is organized as follows. Section II describes the TVC system. In section III, two topologies are proposed and analyzed. Section IV explains the two analyzed reconfiguration strategies. Section V specifies the simulation conditions and some results are given.

\section{TVC SYSTEM}

Thrust Vector Control (TVC) system controls the rocket trajectory using two actuators that will move the thruster. These actuators are placed $90^{\circ}$ from each other, in order to almost decouple the rotation in two orthogonal axes. The thruster movement includes two variables: the inclination angle between its axis and the rocket axis $\left(\theta-\right.$ between $0^{\circ}$ and $\left.6^{\circ}\right)$ and its direction $\left(\varphi-\right.$ between $0^{\circ}$ and $\left.360^{\circ}\right)$, as shown in Fig. 1 and Fig. 2.

Because of the effort added of both actuators, equations (1) and (2) calculate the speed reference of each machine for a maximum inclination of the thruster $\left(\theta=6^{\circ}\right)$ in $\mathrm{rad} / \mathrm{s}$ depending on the angle $\varphi$.

$$
\begin{aligned}
& \Omega_{1_{\text {ref }}}=100 \cos (\varphi) \\
& \Omega_{2_{\text {ref }}}=100 \sin (\varphi)
\end{aligned}
$$

The TVC system profile of utilization is difficult to precise, because strong resistance forces applied in different directions, as the thrust has to ensure the imposed trajectory. Considering the duration of use, the thruster of the lower levels run during approximately 3 minutes, as the upper level run during some hours, depending of the rocket's mission.

\section{FAUlt-TOLERANT CONVERTER TOPOLOGIES}

Both topologies analyzed in this study have two symmetrical six-phase open-end winding motors. In comparison to regular topologies with wye-coupling threephase machines, the topologies proposed in this study are more adaptable to high-power and fault-tolerant applications. At first, a higher number of phases reduces the magnitude of current on each phase for the same power. Furthermore, the supplementary phases take the role of DoF assuring faulttolerance of the system. Open-end windings improve faulttolerance performance by adding one DoF in comparison to the

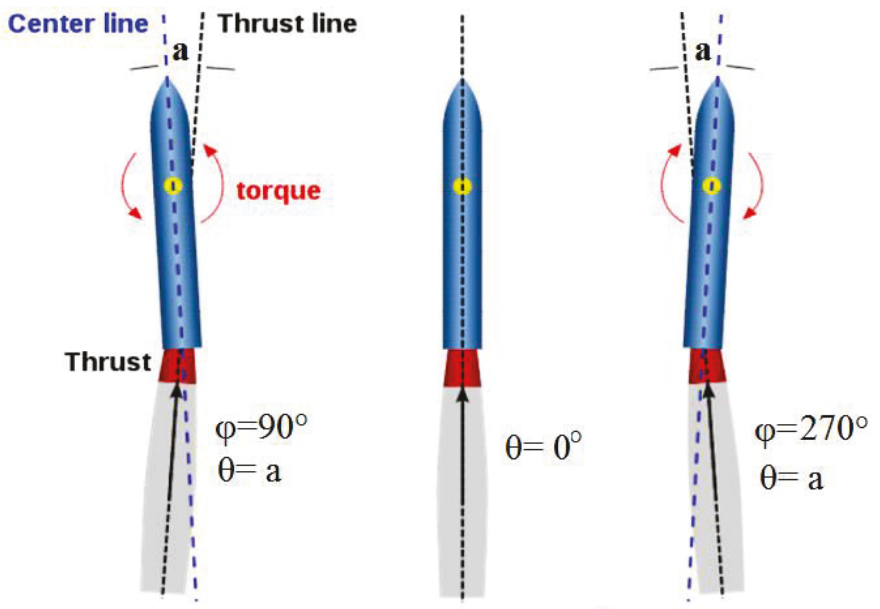

Fig. 1: Representation of the torque generation under 3 different thrust inclinations.

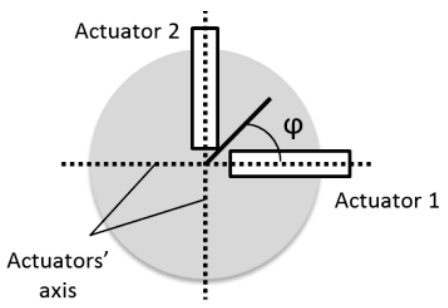

Fig. 2: Angle $\varphi$ representation with actuators' axis as reference

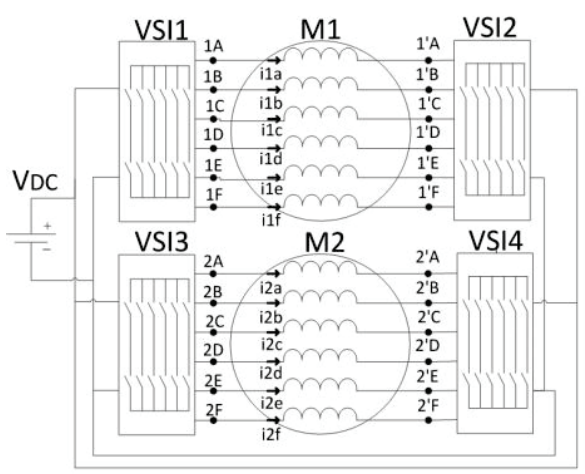

Fig. 3: The H-bridges topology

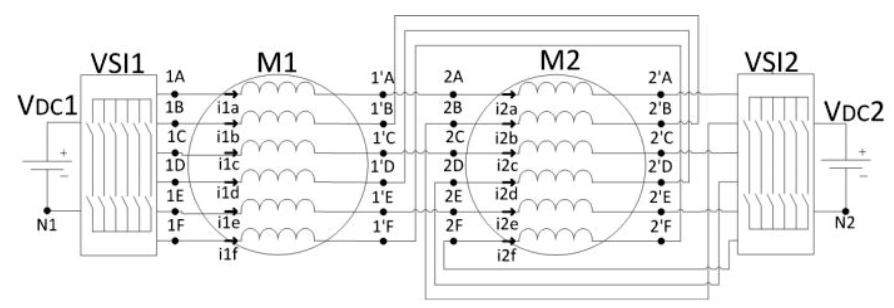

Fig. 4: The RIMM topology

wye-coupling machine and also by the independent supplying aspect [1][4]. However, those topologies need a high number of transistors (two inverter legs per phase).

The H-bridges topology (Fig. 3) is composed by two machines independently supplied. This topology can be already found in some naval and aeronautic applications. The control of this topology is simple, but needs a high number of switches $\left(N_{\text {Sw }}\right)$ (48 switches for 24 inverter legs).

The second topology analyzed in this paper is named RIMM (Redundant Inverter Multiple Machine) (Fig. 4). In the interest of halving the power electronic components, the 
machines are connected in series. Two DC-sources supply the topology, representing a redundancy of the source, but, at the same time, reducing one DoF. In this study, the voltage between the negative potential points of the sources $\left(\mathrm{v}_{\mathrm{n} 1 \mathrm{n} 2}\right)$ is not controlled. However, this voltage can be controlled to increase the system performance in case of short-circuit inverter fault [7].

The independent speed and torque control of the machines is ensured by the innovative coupling between them.

$$
\left[I_{2}\right]=[K]\left[I_{1}\right]
$$

$$
\left[\begin{array}{l}
i_{2 a} \\
i_{2 b} \\
i_{2 c} \\
i_{2 d} \\
i_{2 e} \\
i_{2 f}
\end{array}\right]=\left[\begin{array}{cccccc}
1 & 0 & 0 & 0 & 0 & 0 \\
0 & -1 & 0 & 0 & 0 & 0 \\
0 & 0 & 1 & 0 & 0 & 0 \\
0 & 0 & 0 & -1 & 0 & 0 \\
0 & 0 & 0 & 0 & 1 & 0 \\
0 & 0 & 0 & 0 & 0 & -1
\end{array}\right]\left[\begin{array}{l}
i_{1 a} \\
i_{1 b} \\
i_{1 c} \\
i_{1 d} \\
i_{1 e} \\
i_{1 f}
\end{array}\right]
$$

Applying six-phase Concordia transformation $\left(\left[C_{6}\right]\right)$ to equation (3), a symmetrical six-phase machine is decomposed into four decoupled fictitious machines [12]: two homopolar machines and two two-phase machines. Each fictitious machine interacts with some back-EMF harmonics to generate a torque, as shown in TABLE I.

TABLE I. HARMONIC EMF FOR EACH FICTITIOUS MACHINE

\begin{tabular}{|c|c|c|c|c|}
\hline $\begin{array}{c}\text { Six-phase } \\
\text { machine }\end{array}$ & $\begin{array}{c}\text { First } \\
\text { homopolar } \\
\text { machine } \\
\text { (h1) }\end{array}$ & $\begin{array}{c}\text { Secondary } \\
\text { homopolar } \\
\text { machine } \\
\text { (h2) }\end{array}$ & $\begin{array}{c}\text { Main } \\
\text { machine } \\
(\mathbf{m} \boldsymbol{\alpha} \mathbf{m} \boldsymbol{\beta})\end{array}$ & $\begin{array}{c}\text { Secondary } \\
\text { machine } \\
\mathbf{( s \boldsymbol { \alpha }} \mathbf{s} \boldsymbol{\beta})\end{array}$ \\
\hline $\begin{array}{c}\text { Back-EMF } \\
\text { harmonics }\end{array}$ & $\begin{array}{c}\mathrm{H} 0, \mathrm{H} 6, \\
\mathrm{H} 12, \ldots\end{array}$ & $\mathrm{H} 3, \mathrm{H} 9, \ldots$ & $\begin{array}{c}\mathrm{H} 1, \mathrm{H} 5, \mathrm{H} 7, \\
\mathrm{H} 11 \ldots\end{array}$ & $\begin{array}{c}\mathrm{H} 2, \mathrm{H} 4, \mathrm{H} 8, \\
\mathrm{H} 10, \ldots\end{array}$ \\
\hline
\end{tabular}

The main machine is the one to be controlled to generate the highest torque with less current.

TABLE I. shows that the first homopolar machine $\left(h_{l}\right)$ and the secondary machine $(s \alpha s \beta)$ interact with even harmonics of the back-EMFs after the Concordia transformation. Even backEMFs harmonics are null in regular electric machines because of morphologic aspects of winding symmetry. Anyway, BackEMF of the analyzed model is sinusoidal; so the total average torque of the six-phase machines is generated by the mainmachine.

Fig. 5 illustrates equations (8) and (9) representing the series connection of the fictitious machines, because they conduct the same currents. As mentioned above, two secondary machines do not generate torque, which can lead to a simple and independent control of M1 and M2 torque by controlling $I_{\alpha \beta 1}$ and $I_{\alpha \beta 2}$ respectively.

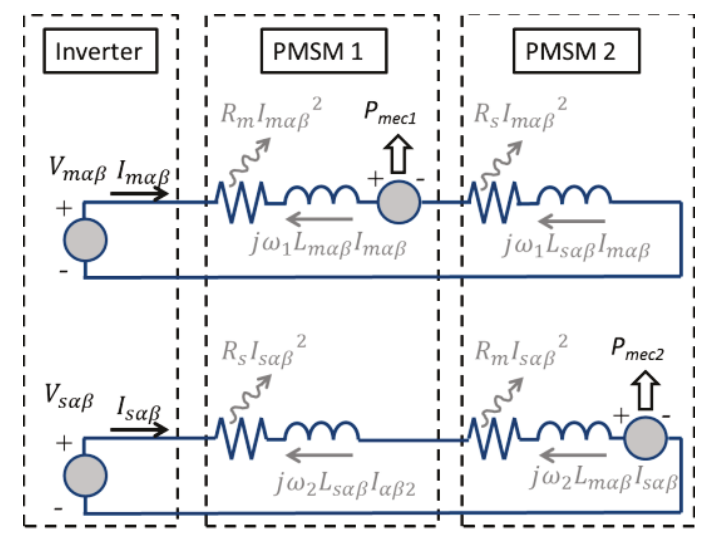

Fig. 5: Scheme showing the series connection between the fictitious machines

$$
\begin{aligned}
& {\left[I_{1_{\alpha \beta}}\right]=\left[C_{6}\right][K]^{-1}\left[C_{6}\right]^{T}\left[I_{2 \alpha \beta}\right]} \\
& {\left[I_{1_{\alpha \beta}}\right]=\left[\begin{array}{cccccc}
0 & 1 & 0 & 0 & 0 & 0 \\
1 & 0 & 0 & 0 & 0 & 0 \\
0 & 0 & 0 & 0 & 1 & 0 \\
0 & 0 & 0 & 0 & 0 & -1 \\
0 & 0 & 1 & 0 & 0 & 0 \\
0 & 0 & 0 & -1 & 0 & 0
\end{array}\right]\left[I_{2_{\alpha \beta}}\right]} \\
& {\left[\begin{array}{l}
i_{h 11} \\
i_{h 21} \\
i_{m \alpha 1} \\
i_{m \beta 1} \\
i_{s \alpha 1} \\
i_{s \beta 1}
\end{array}\right]=\left[\begin{array}{c}
i_{h 12} \\
-i_{h 22} \\
i_{s \alpha 2} \\
-i_{s \beta 2} \\
i_{m \alpha 2} \\
-i_{m \beta 2}
\end{array}\right]} \\
& {\left[\begin{array}{l}
i_{m \alpha 1} \\
i_{m \beta 1}
\end{array}\right]=\left[\begin{array}{c}
i_{s \alpha 2} \\
-i_{s \beta 2}
\end{array}\right] \rightarrow\left[I_{m 1}\right]=\left[I_{s 2}\right]^{*}} \\
& {\left[\begin{array}{l}
i_{s \alpha 1} \\
i_{s \beta 1}
\end{array}\right]=\left[\begin{array}{c}
i_{m \alpha 2} \\
-i_{m \beta 2}
\end{array}\right] \rightarrow\left[I_{s 1}\right]=\left[I_{m 2}\right]^{*}}
\end{aligned}
$$

\section{RECONFIGURATION MODES}

In order to reduce the amplitude of the currents in degraded mode, simple reconfiguration strategies may be applied to the system. The two hardware reconfigurations analyzed in this paper try to reduce the current in the faulty phase. A hardware reconfiguration consists in imposing the state of some switches (open or close) without changing the control strategy. As all phases are independently supplied by two inverter legs, the hardware reconfiguration is only applied to the corresponding leg supplying the faulty phase.

Reconfiguration 1 opens all the switches of the corresponding leg as shown in Fig. 6. On this example, the top switch of the first leg of the VSI1 is short-circuited, than both transistors of the first leg of VSI2 are voluntarily opened.

The objective of this strategy is to break the loop that allows the conduction of the first phase current. Even if the transistors of the inverter leg are opened, the free-wheeling diodes allow the current to flow in one direction.

Reconfiguration 2 will control the corresponding leg of the second inverter to reproduce the same short-circuit faulty leg as the VSI1 (Fig. 7). As a consequence, the phase (or the phases)

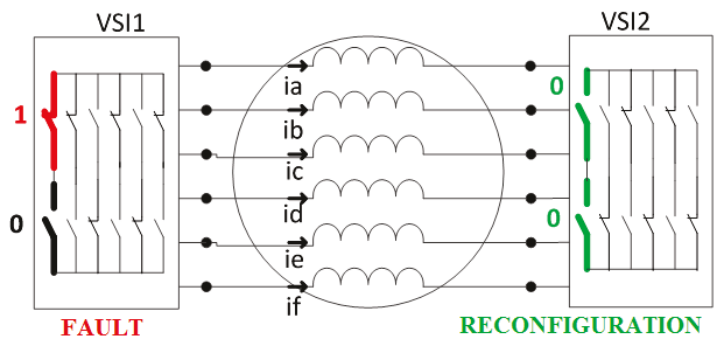

Fig. 6: Representation of the reconfiguration strategy 1.

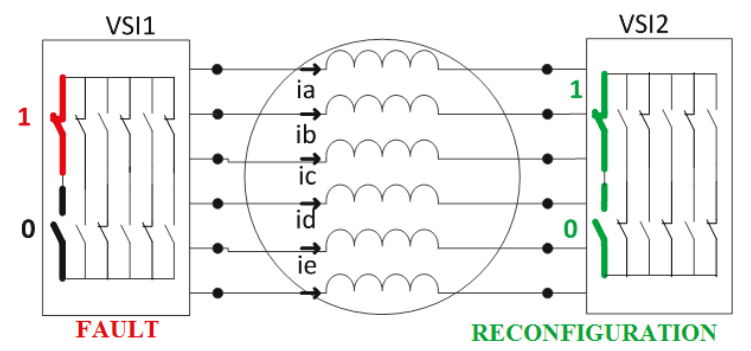

Fig. 7: Representation of the reconfiguration strategy 2. 
supplied by the faulty legs will be connected to the same potential in both sides. This reconfiguration strategy was once analyzed in [7].

This reconfiguration reduces the voltage on the phase supplied by the faulty leg. Similarly to the reconfiguration 1 , the current of the faulty phase is not nullified, because of the Back-EMF and the voltage $v_{n 1 n 2}$, the last one is only for the RIMM topology.

In general, a reconfiguration needs a fault detection system that detects precisely and quickly the fault in order to activate the reconfiguration strategy. For the first reconfiguration strategy implementation, fault detection system has to identify the faulty phase, while the reconfiguration 2, needs information of the faulty switch and the faulty mode (open-switch or shortcircuit). Even so, the fault-detection strategies are not analyzed in this paper. For all simulations, it was took into account that the faulty switch and the fault type was well detected enough to implement the desired reconfiguration.

\section{Simulation Results}

\section{A. Drive model}

Machine's parameters are not similar for both topologies. Because of aerospace constraints, the DC-bus voltage is fixed, so the drive has to be adapted to it. The number of coil turns has been defined by taking into account the drive normal mode performance, impacting on the phase resistance, inductance and magnetic flux, as shown in TABLE II.

TABLE II. MACHINE PARAMETERS

\begin{tabular}{|c|c|c|}
\hline & H-bridges & RIMM \\
\hline Coil turns & $\mathrm{N}$ & $\mathrm{N}^{*} 0.78$ \\
\hline$R_{s}$ & $0.043 \Omega$ & $0.026 \Omega$ \\
\hline$L_{m \alpha \beta}$ & $0.455 \mathrm{mH}$ & $0.277 \mathrm{mH}$ \\
\hline$L_{s \alpha \beta}$ & $0.455 \mathrm{mH}$ & $0.277 \mathrm{mH}$ \\
\hline$L_{h}$ & $0.455 \mathrm{mH}$ & $0.277 \mathrm{mH}$ \\
\hline$e_{q 1} / \Omega$ & 0.32 & 0.25 \\
\hline $\begin{array}{c}\text { Pole pairs } \\
\text { number }(\mathrm{p})\end{array}$ & 7 & 7 \\
\hline
\end{tabular}

\section{B. Control diagrams}

As shown by Fig. 8 and Fig. 9, both topology control diagrams of the simulated system are composed of two loops: the internal current loop and the external speed loop. In the real TVC system there's still an external position loop. In both topologies, there is one speed corrector for each machine.

Regarding the current controllers, there are six PI correctors for one machine in the H-bridge topology: two for the main machine, two for the secondary machine and two for the two homopolar machines. The current references of the main machines are defined by the speed controller while the others have null references.

As currents are coupled in RIMM topology and first homopolar current is null because of the structure, there are only five current controllers for both machines. The current references respect the equations (8) and (9). The current references of the main machine of the M1 are defined by the speed controller of the machine M1. The current references of the secondary machine of the M1 are defined by the speed controller of the machine M2. The details are given in Fig. 9

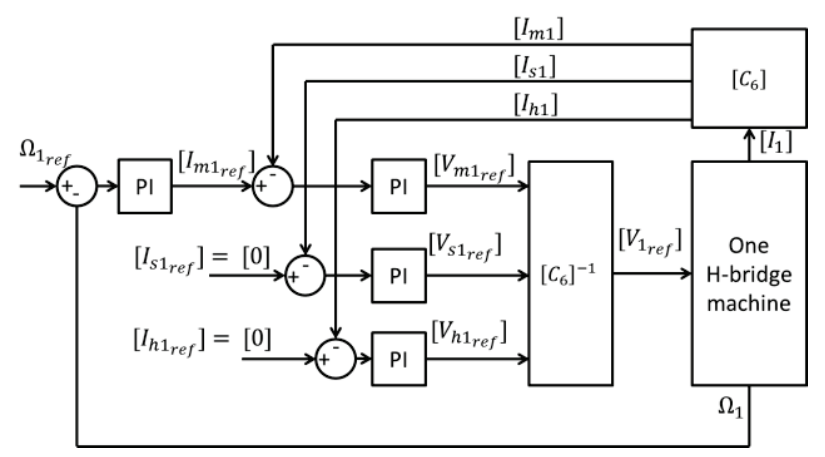

Fig. 8: Control diagram of one H-bridge machines

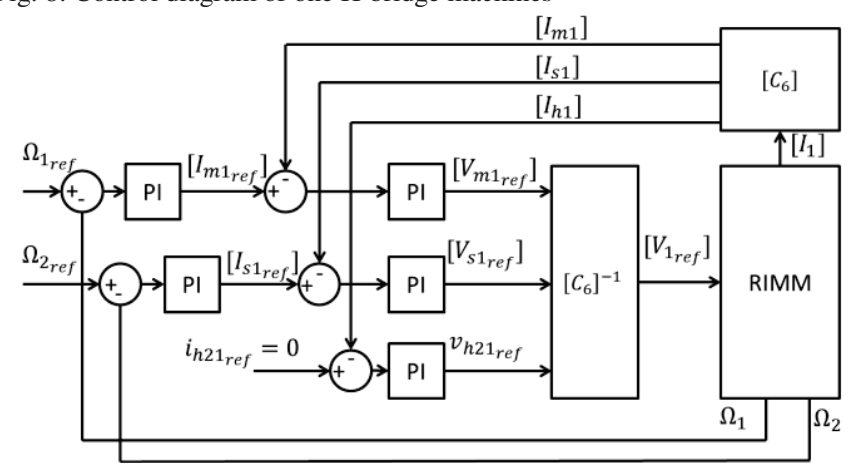

Fig. 9: Control diagram of RIMM topology

\section{Speed reference}

In the thruster pay-load, two kinds of speed references must be ensured by each topology. Both speed references represent the speed needed to obtain the maximum inclination $\left(\theta=6^{\circ}\right)$ of the thruster in comparison to the rocket axis. For each topology, the sizing of the inverter will be determined by considering the worst case (in the degraded modes). As a consequence, all operating points below the considered ones are available.

As H-bridges topology has the machines independently supplied, the highest peak-current will be generated when the displacement direction is $\varphi=0^{\circ}$ on one actuator axis and $\Omega_{\mathrm{ref}}=$ $100 \mathrm{rad} / \mathrm{s}$ for the other actuator axis.

On other hand, as the two machines are in series, the most constraining speed reference for RIMM topology is when displacement at $\varphi=45^{\circ}$, with both machines running simultaneously at $\Omega_{\text {ref }}=70.7 \mathrm{rad} / \mathrm{s}$.

\section{Faults simulation}

For the short-circuit fault simulation, the top switch of the phase A of the inverter VSI1 in both topologies is shortcircuited. To avoid a short-circuit of the DC-bus, the bottom switch of the same leg has to be 'open'.

For the reconfiguration 1 simulation, both switches of the phase A of the inverter VSI2 will be opened, similar to Fig. 6. In the reconfiguration 2, the top switch of the phase A of the inverter VSI2 will be closed, and the bottom switch of this same inverter leg will be opened, as Fig. 7.

\section{E. Results and analysis}

Fig.10 presents the peak currents for the two different topologies presented in section III under healthy and faulty modes at the most constraining speed reference.

Peak-currents $\left(I_{p k}\right)$ are obviously higher in faulty mode than in healthy one because the currents in the healthy phases have to increase to reach the required speed and torque as before the fault, as shown in Fig. 11 to Fig. 15. 


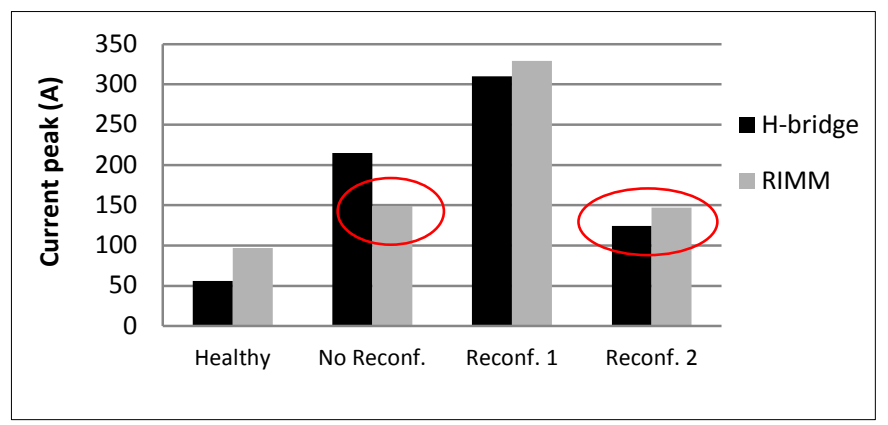

Fig.10: Peak currents obtained under normal mode and under short-circuit switch fault operations with two proposed topologies.

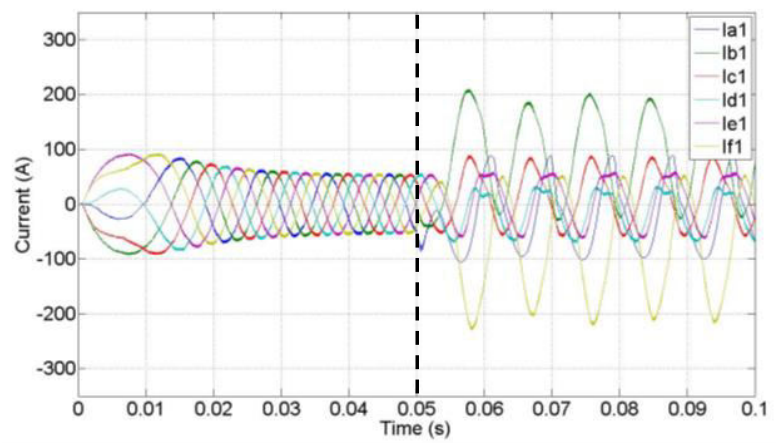

Fig. 11: H-bridge's currents without reconfiguration.

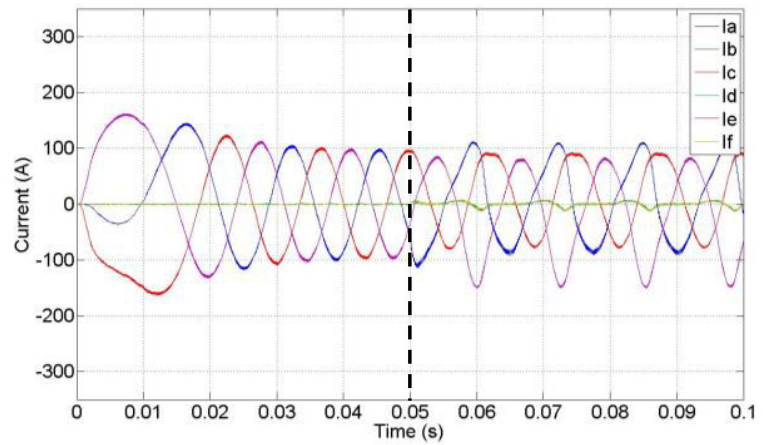

Fig. 12: RIMM's current without reconfiguration.

Fig. 11 and Fig. 12 give the obtained currents of each topology before and after a short-circuit switch fault without reconfiguration. High homopolar harmonics in $\mathrm{H}$-bridge currents explain the higher peak-currents and current phases more unbalanced. On the other hand, the RIMM topology doesn't have a path for the even homopolar current harmonics.

Because of the special series connection, when both machines have exactly same running conditions (speed reference, resistance force and initial rotor position) three of six current phases tend toward zero, consequently, the peak of the other three currents are high.

By observing Fig. 10, the reconfiguration 1 has the highest peak-currents for both topologies in both speed references in comparison with all the other modes. The Fig. 17 and Fig. 18 also show a high oscillation of the torque for both topologies.

Differently than the reconfiguration 1, the second reconfiguration strategy reduces the peak-currents of both topologies, comparing to the no reconfiguration degraded mode. Otherwise, the graphic shows a higher impact of the reconfiguration for the $\mathrm{H}$-bridges topology than for the RIMM topology, a reduction of more than $40 \%$ in the peak-current and torque oscillation for the H-bridges topology while RIMM's peak-current stays almost unchanged (about 150A). The

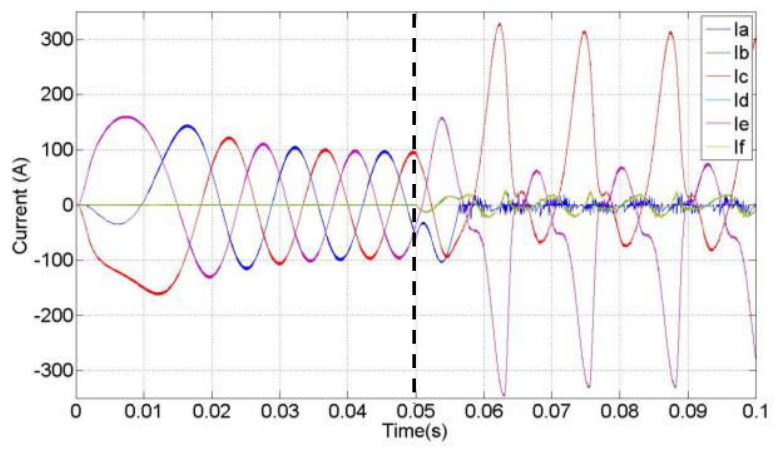

Fig. 13: RIMM's current with reconfiguration 1.

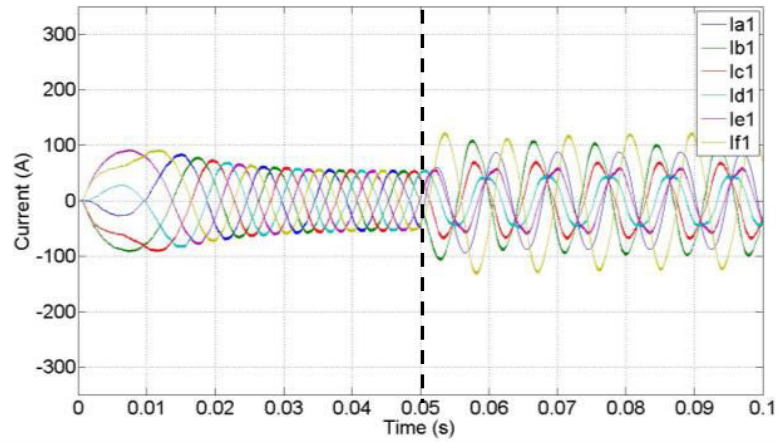

Fig. 14:H-bridge's current with reconfiguration 2.

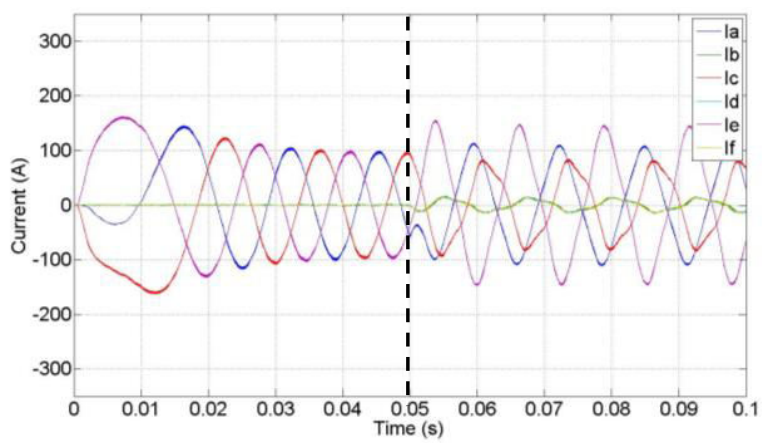

Fig. 15:RIMM's current with reconfiguration 2.

reduction of the homopolar currents explains these results. Without reconfiguration, the RIMM topology conducts low homopolar currents because of the two isolated source neutral points.

Beside of it, the reconfiguration 2 is less adaptable to the RIMM topology because the current conducted by the faulty leg is generated by the Back-EMF plus the voltage $v_{n 1 n 2}$.

For a general comparison, the minimum value of peakcurrent is obtained in reconfiguration 2 with the H-bridges topology (around 125A), 16\% lower than RIMM's peak current at the same reconfiguration, but with twice more switches. The global apparent power (in VA) $\left(S_{g l}\right)$ of the " $\mathrm{H}$ bridges" topology is in this case roughly $168 \%$ higher than with the RIMM topology, as calculated by equations (10) and (11) and shown in Fig. 16.

$$
\begin{aligned}
& S_{s w}=V_{D C} * I_{p k} \\
& S_{g l}=N_{s w} * S_{s w}
\end{aligned}
$$

Furthermore, RIMM topology does not need reconfiguration strategies to reduce significantly its required investments, being exempt of reconfiguration operational constraints. On the other hand, H-bridges' global apparent power is almost three times higher without reconfiguration (Fig. 16). 


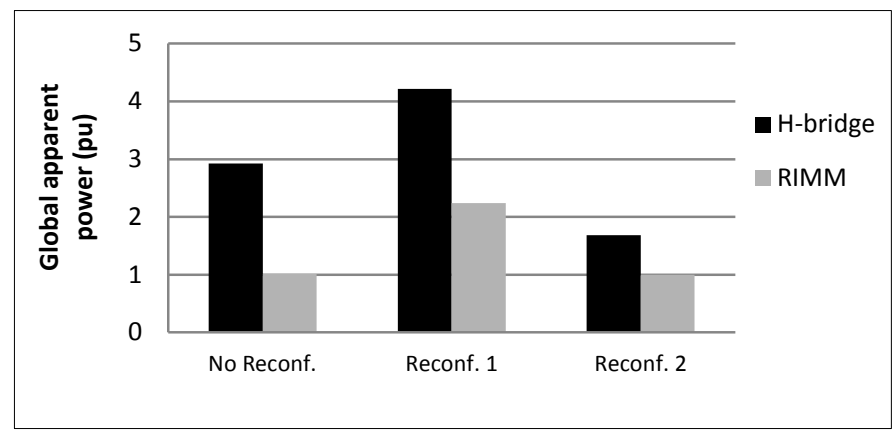

Fig. 16: Comparison of the global power of the switches set (lower value being taken as reference).

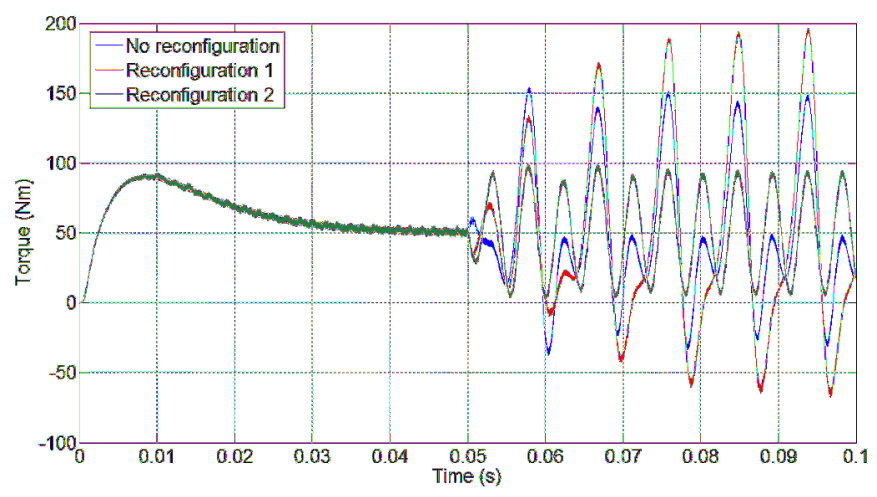

Fig. 17: Torques of the H-bridge topology for two different reconfigurations

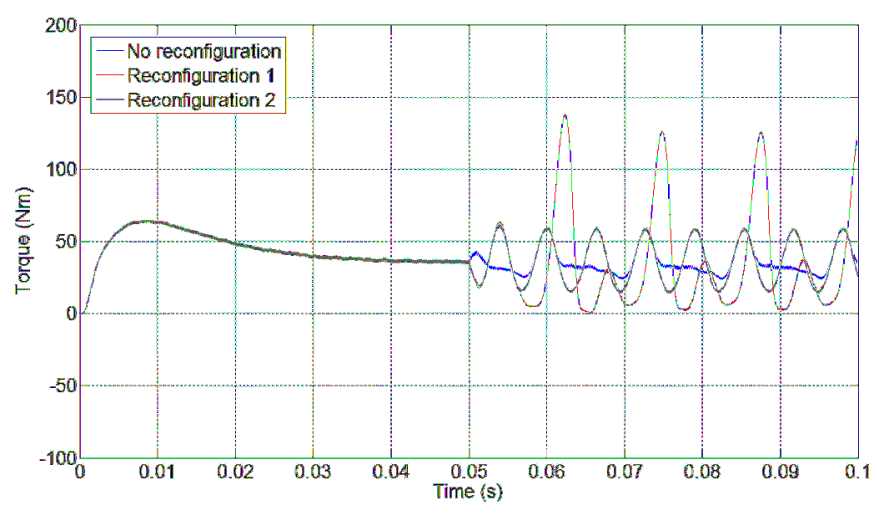

Fig. 18: Torques of the RIMM topology for two different reconfigurations

Another comparison criterion that can be considered is the torque quality obtained with different reconfigurations for each topology. The results are reported in Fig. 17 for the H-bridge topology and in Fig. 18 for the RIMM topology. As shown above, a high peak of currents leads to generally a high peak of the torque if there is no applied control strategy. This is true in our study case where the torque ripple given in the H-bridge topology is high due to a high peak of currents.

However, the robustness and effectiveness of RIMM topology are higher than the ones in the H-bridge topology. Fig. 18 shows that the torque ripple after the fault is smaller in comparison with the H-bridge topology leading to a less vibration of the associated mechanical systems. This point is sometime important to take into account for system design.

\section{CONCLUSION}

This paper compares two topologies comprising each one inverter legs and two symmetrical six-phase machines. The comparison criterion is the global sizing of the inverter, so the global apparent power. The RIMM topology needs 12 inverter legs in comparison with the 24 inverter legs of the H-bridges topology. As the voltage constraint, due to identical DC- voltage source, is the same for the two topologies, it is the peak current which is the determining factor for the transistor's apparent power.

As the short-circuit inverter switch induces on the peak current a more severe constraint than the normal mode operation, the comparison is done in this case, considering then three different strategies of control.

The RIMM topology shows a better performance in term of power electronic components and power rate of inverters, for the two best available strategies in case of inverter switch short-circuit fault. Even if the H-bridge peak-currents for reconfiguration 2 were the lowest peak-currents obtained, RIMM's global apparent power is lower without reconfiguration or with reconfiguration 2 .

\section{REFERENCES}

[1] J. Bennett, G. Atkinson , B. Mecrow and D. Atkinson "Fault tolerant design considerations and control strategies for aerospace drives", IEEE Trans. Ind. Electron., vol. 59, no. 5, pp.2049-2058 2011

[2] M. Villani , M. Tursini , G. Fabri and L. Castellini "High reliability permanent magnet brushless motor drive for aircraft application", IEEE Trans. Ind. Electron., vol. 59, no. 5, pp.2073 -2081 2012

[3] L. de Lillo , L. Empringham , P. Wheeler , S. Khwan-On , C. Gerada , M. Othman and X. Huang "Multiphase power converter drive for faulttolerant machine development in aerospace applications", IEEE Trans. Ind. Electron., vol. 57, no. 2, pp.575 -583 2010

[4] B. A. Welchko, T. A. Lipo, T. M. Jahns, and S. E. Schulz, "Fault tolerant three-phase AC motor drive topologies: A comparison of features, costs, and limitations," IEEE Trans. Power Electron., vol. 19, no. 4, pp. 1108-1116, July 2004.

[5] R. R. Errabelli and P. Mutschler, "Fault-Tolerant Voltage Source Inverter for Permanent Magnet Drives," IEEE Transactions on Power Electronics, vol. 27, no. 2, pp. 500-508, Feb. 2012.

[6] A. Mohammadpour, S. Mishra, and L. Parsa, "Fault-Tolerant Operation of Multiphase Permanent-Magnet Machines Using Iterative Learning Control," IEEE Journal of Emerging and Selected Topics in Power Electronics, vol. 2, no. 2, pp. 201-211, Jun. 2014.

[7] N. K. Nguyen, F. Meinguet, E. Semail, and X. Kestelyn, "Fault-Tolerant Operation of an Open-End Winding Five-Phase PMSM Drive with Short-Circuit Inverter Fault," IEEE Transactions on Industrial Electronics, pp. 1-1, 2015.

[8] E. Levi, M. Jones, S.N. Vukosavic, H.A. Toliyat, "A Novel Concept of a Multiphase, Multimotor Vector Controlled Drive System Supplied From a Single Voltage Source Inverter", IEEE Transactions on Power Electronics, vol. 19, no. 2, March 2004, pp. 320-335.

[9] D. Dujic, M. Jones, E. Levi, and O. Lopez, "DC-bus utilisation in seriesconnected multi-phase machines supplied from a VSI with a composite phase number," Electrical Machines (ICEM), 2010 XIX International Conference, Rome, 2010, pp. 1-6.

[10] A. Iqbal , S. Vukosavic , E. Levi , M. Jones and H. A. Toliyat "Dynamics of a series-connected two-motor five-phase drive system with a single-inverter supply", Conf. Rec. IEEE IAS Annu. Meeting, pp.1081 -1088 2005

[11] E. Semail, E. Levi, A. Bouscayrol, and X. Kestelyn, "Multi-machine modelling of two series connected 5 phase synchronous machines: effect of harmonics on control," Power Electronics and Applications, 2005 European Conference, Dresden (Germany), Sept. 2005, pp. 1-10

[12] X. Kestelyn, E. Semail, "A Vectorial Approach for Generation of Optimal Current References for Multiphase Permanent Magnet Synchronous Machines in Real-time", IEEE Transactions on Industrial Electronics, Vol 58, №11, pp5057-5065, Nov 2011. 